\title{
Risk, Covid-19 and hospital care in Mexico City: Are we moving toward a new medical practice?
}

Riesgo, Covid-19 y atención hospitalaria en la Ciudad de México: ¿Hacia una nueva práctica médica?

Rubén Muñoz Martínez ${ }^{1}$

Fecha de recepción: 2 de abril de 2021

Fecha de aceptación: 15 de julio de 2021

1 - Nacionalidad: Mexicana. Grado: Doctorado en Antropología Social y Cultural. Adscripción: Centro de Investigaciones y Estudios Superiores en Antropología Social (CIESAS), Ciudad de México. DiD ORCID: https://orcid.org/0000-0002-0631-8816

| Correo electrónico: rubmuma@hotmail.com 


\section{Abstract}

Covid-19 pandemic has entailed new challenges for health care in the Mexican public health sector, producing changes in clinical practices that are now handling patients infected with covid-19 and also outpatient consultations at tertiary-level care hospitals. Some of these challenges are related to the perception of risk held by physicians regarding the possibility of contracting or transmitting covid-19 during their work, and to the management of risk from the standpoint of biomedical organizational culture linked to the material and symbolic conditions of public health services predating the pandemic. We analyze these issues from an anthropological research based on in-depth interviews to physicians that work with covid-19 patients at "Covid-19 hospitals" or "hybrid hospitals" in Mexico City. Covid-19 has arrived in social relations and perceptions of risk in the arena of health care and involves knowing and transforming some structural and symbolic conditions, resignified with the pandemic, for proper medical care.

Keywords: Covid-19, risk perception, health care workers, hospital care, biomedical organizational culture.

\section{Resumen}

El Covid-19 implica nuevos retos para la atención en el sistema público de salud mexicano, a partir de la modificación de la práctica clínica que ahora atiende a pacientes con Covid, y a aquellos que acuden a la consulta externa de los hospitales. Algunos de estos retos comprometen la adecuada atención médica y se relacionan con la percepción del riesgo de los médicos, respecto a la posibilidad de infectarse o de transmitir el Covid durante su trabajo, y con la gestión del riesgo desde la cultura organizacional biomédica articulada a las condiciones materiales y simbólicas de los servicios de salud públicos preexistentes a la pandemia. Se analiza esta problemática desde una investigación antropológica basada en entrevistas en profundidad a médicos/as que atienden Covid en "hospitales Covid" e "híbridos" de la Ciudad de México. La pandemia ha aterrizado en las relaciones sociales y percepciones de riesgo en el campo de la salud e implica conocer y transformar algunas de las condiciones simbólicas y estructurales, ahora resignificadas, para una atención adecuada.

Palabras clave: Covid-19, percepción de riesgo, personal de salud, atención médica hospitalaria, cultura organizacional biomédica. 


\section{Introduction}

$\mathrm{I}$ $\mathrm{n}$ this article we analyze the emerging challenges for an adequate medical practice that broaches the perception of risk held by doctors working with covid $-19^{2}$ at tertiary-level public hospitals in Mexico City, as linked to the rise of a new biomedical organizational culture (BOC) designed to manage risk. Within a framework of priorities determined by dominant epidemiology from the standpoint of impact on health care during the present covid-19 pandemic, medical anthropology allows for tracing possibilities (Jaffre, 2012) to reflect on and for intervention in solving this problem. This article adds to some of the contributions that medical anthropology has made to the public health emergencies such as N1H1 (Singer, 2009, Menéndez, 2014) or Ebola (Venables and Pellecchia, 2017), carrying out theoretical and/or applied proposals to understand the articulation between social and cultural behaviors, structural conditions, and their impact on health.

From the anthropological perspective that links the micro and macro levels of analysis, and from the points of view and practices of the actors, we understand risk to be a social construct that is culturally determined by the members of a society that, according to Douglas (1986), can be used to carry out social evaluations on probabilities and values in light of a threat, which will include expertise (Lupton, 1999). BOC refers to the material, financial and social dimensions, as well as the symbolic and interpretative dimensions, of the biomedical care that takes place in a given institution or organization (Muñoz, 2018), which, in turn, defines and is redefined by the social representations and institutionalized practices of the actors themselves. In the case of doctors, their perception of risk and the BOC in which they work cannot be dissociated from the vulnerability they feel, turning them into a vulnerable group themselves (Nichter, 2006), due to the potential effect on their own health and that of patients with regard to the medical care provided. The BOC manages risk based on regulations, protocols and emerging practices regarding covid-19, and here we analyze their linkage to the perception of risk held by doctors and the implications for the medical practice as linked to the following dimensions: a) hospital reconversion into covid-19 or hybrid hospitals; b) medical personnel and medical specializations available; $c$ ) the departments in which they work $d$ ) the adaptation of hospital spaces and sanitation recommendations e) the use of Personal Protection Equipment (PPE) and how it limits the care provided.

Based on these dimensions, the questions we answer in this article are: Has the covid-19 pandemic changed the medical practice at the tertiary-level of public health care in Mexico City? What are some of the main symbolic and structural conditions that determine the adaptation of the medical practice under these new circumstances?

On December 31, 2019, in the city of Wuhan, China, an alert was issued regarding the presence of a new respiratory disease, given the name of covid-19, caused by a new virus: SARS-CoV-2. On March 11,2020 , the World Health Organization officially declared the "pandemic". America is the region in the world with the highest number of health professionals infected with covid-19, and Mexico is the country with the highest number of deaths by covid-19 in the world. Of the total number of cases detected

2- To avoid reproducing stigma and discrimination we use lower case letters (covid-19), in the same way as it is agreed to refer to aids. 
in health care workers (HCW) through August 2020, 97,632, 24\% are doctors. Mexico and the United States represent $85 \%$ of all deaths in HCW in America (Chertorivski et al., 2020).

Early in 2020, the call was made to strengthen public health strategies to handle the health emergency with the provision of and proper use of PPE for medical personnel (Kim et al., 2020). In countries like China or Brazil, HCW denounced extenuating workdays and insufficient or inadequate PPE, among other problems, that did not comply with the recommendations to protect the health of HCW (Jackson-Fiho et al., 2020; Kang et al., 2020), a situation that also holds true for Mexico (Chertorivski et al., 2020), which in turn leads to HCW to be perceived as vulnerable to contagion.

Some recent quantitative studies indicate that with regard to covid-19, the above is linked to prior experience, contact with covid positive patients, the department in which they work and even to the capacity of the health system they work for (Chew et al., 2020; Peres et al., 2020). HCW concerns and uncertainties, implicit in social expressions about the risk of infection with SARS-CoV-2 and the conditions under which they practice medicine, may have psychological effects (stress, anxiety, depression, insomnia, etc.) that may affect HCW care, understanding and ability to make decisions, as well as affecting long-term well-being, even influencing the quality of care provided for healthy users or those suspected or diagnosed with covid-19 (Kang et al., 2020).

Through January 2020, there was very few qualitative studies in the world, based on fieldwork, published on the perception of risk that doctors held regarding experiences when providing care to covid-19, one of them carried out by Liu et al. (2020) in China. As far as we know, there has been no other publication, based on fieldwork, in Mexico that links the perception of risk to the dimensional structure of public health policies and the emergence of new BOCs, exploring the changes taking place in medical practice and challenges in the short and mid-term. Understanding this will allow us to establish intervention strategies intended to prevent deficient care and guarantee that doctors can feel safe in their workplaces and that the BOC their clinical practice subscribes to can provide the material and cultural inputs that are appropriate.

\section{1. $T$ he Epidemiological Context}

Based on World Bank estimates through August $3^{3}$, Mexico exhibits a rate of 500.4 deaths per million inhabitants due to covid-194, with 559,560 cases confirmed through PCR testing, 77,730 suspicious and 64,414 confirmed deaths; 38,923 are active cases, that is to say they began within the preceding 14 days. Among the PCR tests used to confirm diagnosis, 43\% ended up being positive. Health authorities have announced that the curve of estimated and recovered cases and deaths show a downward trend as compared to the rising trend observed until the middle of July. Of the 31,030 hospital beds available in the country to handle covid-19 patients, 35\% are occupied (10,834), although 12 states and Mexico City have recorded higher than average hospital occupancy. Of the 10,201 hospital beds available throughout the country to care for critical patients requiring intubation, $30 \%$ are occupied, although 13 states and Mexico City have an occupancy rate above this average.

3- Period in which the field work was carried out.

4- Press Conference, Daily report on coronavirus COVID-19 in Mexico, Secretariat of Health, August 31, 2020. 
The first report on excess mortality due to the covid-19 pandemic in Mexico indicates that, compared to the same period in 2019, until August 2nd 2020 there had been an excess mortality of 59\% in the group of 45-65 years, while in the group aged 20 to 44 years it was $40 \%$, and in the group aged 65 and over, the excess mortality was $31 \%$. Covid-19 had a significant impact on the mortality of people aged 20-65 years, as well as those over 65, in 2020 (Daily report on coronavirus covid-19 in Mexico, September 05, 2020). At the same time, it points out the differentiated behavior of the pandemic in Latin America with respect to other contexts, such as Europe, in which the percentage of excess mortality was higher in those over 65 than in other ages (Fantin et al., 2021).

\section{Mexico's Health Measures to Counter the Pandemic}

The Under-Secretary of Prevention and Promotion of Health in Mexico has pointed out, during the daily press conferences offered to report on the pandemic in Mexico, that investment in health has steadily dropped since the eighties in response to the neoliberal politics implemented in the last several administrations, which in turn has made the health system deficient in both human resources and infrastructure, making it vulnerable to collapse in an emergency situation such as the pandemic.

To avert a catastrophic situation -in which thousands of people might not have received hospital care given the sheer numbers of persons infected with covid-19- health authorities employed a strategy known as "hospital reconversion". Not only did this facilitate the increase in numbers of overall hospital beds available at the secondary and tertiary levels in the country, but also the number of beds available in intensive care, and at the same time the availability of respirators for critical patients. In some cases, this reconversion entailed some hospitals being designated exclusively for the care of covid-19 patients and became known as "Covid-19 hospitals"; yet others continued offering care in all fields of specialization, and in addition had a wing or floor designated for the care of covid-19 patients, and became known as "hybrids". Through these actions, it was possible for the country's public health system to facilitate 31,126 beds for the exclusive hospitalization of covid-19 patients and another 10,548 for patients requiring intensive care.

Regarding pandemic mitigation measures in Mexico, the National Drive for Healthy Distancing (Jornada Nacional de Sana Distancia) began on March 23 and consists of suspending all activities deemed "non-essential", such as education and many of an economic nature. At public hospitals, this translated into a drop of $60 \%$ in consultations, primarily of patients considered to be at "high risk" due to comorbidities. Although this averted the possibility of infection with covid-19 because of the need for transportation and through moving around in a hospital, they were left without follow-up, which likely will have implications in the evolution of their ailments.

\section{Methodology}

This is a qualitative-type study based on semi-structured telephone interviews and on grounded theory (Glasser \& Strauss, 1967), from the paradigm of social constructivism (Berger and Luckman, 1966). From this point of view, "empirical reality is seen as an ongoing interpretation of meanings 
produced by individuals inserted in a common observation project " (Sudabby, 2006) The grounded theory was applied mainly considering the importance of scientific induction from the empirical data, in a novel topic that to date had not been investigated. From this approach, scientific evidence is generated and discussed with the scarce existing findings regarding covid-19 and/or other pandemics with similar characteristics related to the study problem.

\subsection{Data collection}

Doctors, male and female, from the Secretaría de Salud (SSA), the Instituto de Seguridad y Servicios Sociales de los Trabajadores del Estado (ISSSTE) and the Instituto Mexicano del Seguro Social (IMSS) ${ }^{5}$, who work in covid-19 hospitals and hybrid hospitals in Mexico City were interviewed. We understand the three public systems as the same unit of analysis (multi-sited) regarding covid-19 care and risk perception by sharing structural, organizational and health care characteristics since the arrival of the pandemic.

The snowball technique was employed to invite doctors to collaborate as respondents through previous contacts provided by the research team; the doctors received a WhatsApp message with a document explaining the nature of the project, which was reiterated orally before the interview, their collaboration was requested, and a date and time for the interview agreed on. In this manner, 70 people were contacted, of which 42 accepted and were interviewed. The ones not accepting or not going through with the interview mentioned that they had "too much work", their workdays were very long (especially in the case of residents), they had sick family members or who had recently died, or they themselves were sick with covid-19. All interviews were conducted in Spanish and were interrupted once the information obtained appeared saturated.

This article includes an analysis of 42 interviews, 35 of them with doctors who work in regional or highly specialized hospitals. We interviewed seven health promotors and doctors at primary care hospitals who perform diagnostic triage, for the purpose of contrast with tertiary care as we explored - from the viewpoint of these doctors - the ways patients access diagnosis, medical care and are referred to the hospitals.

Of the 35 interviews held with doctors working in these hospitals: two of them held senior positions entailing decision-making; 16 are medical residents at Internal Medicine, Medical-Surgical Emergencies, Psychiatry, Pediatrics, Clinical Pathology, and Dermatologic and Oncologic Surgery; and 16 doctors assigned to Critical Care, Medical and Surgical Emergency, Ophthalmology, Otolaryngology, Clinical Pathology, Cardiothoracic Surgery, Urology, Pediatrics and Gynecology; three of the participants are general practitioners. Of the respondents, 17 were women and 18 were men. No pulmonologist or infectologist accepted the invitation to collaborate. The testimonies published in this article include the field of specialization and sex by way of identification (protecting anonymity).

Nevertheless, it is important to clarify that while at the beginning of the pandemic most tertiary-level hospitals decided that the fields of specialization of Pulmonology, Infectology, Internal medicine and Critical medicine were to be in charge of patients hospitalized and/or intubated due to 
covid-19, as the number of cases increased it became necessary for all fields of specialization to collaborate on a shift basis. For this reason, we ended up with a diversified sample of the various specialties that are dealing with covid-19.

The age range of respondents is 26 to 55 years of age, with an average age of 33 . That is to say that the sampling comprises primarily young people; the reason for this is that all of the participating institutions determined that personnel with comorbidities and/or over the age of 65 would not be working. This is known as the "Covid-19 leave". Nevertheless, six (17\%) of the respondents did have comorbidities (mainly hypertension and asthma) but decided to remain on the job for they believed that staying home would be counterproductive for their mental health, or, in the case of residents, the "leave" did not apply. Of the respondents, seven (20\%) were diagnosed with covid-19.

The timeframe for fieldwork encompasses May through September 2020, with 80\% of the interviews held between June and August; the duration of the interviews ranged from 1 to 2 hours.

\subsection{Data analysis}

The empirical data obtained was textually transcribed for subsequent codification and analysis using the program Atlas.ti 8, following the scientific procedure in qualitative research for the classification and analysis of empirical data (Schreier, 2012). The interview recorded was listened two times by the researcher, the transcript of each interview was reviewed on several occasions by him, as well as the coding that he generated in each of them. During the encoding and data analysis we considered previous and emergent categories ${ }^{6}$. In this sense, as the interviews progressed, new questions and categories of analysis emerged that were considered in the design of the script for subsequent interviews and contrasted with the existing literature regarding covid or other epidemics, within an ongoing process of analysis. The material obtained was triangulated, including the data offered by different respondents, recurrent in the units selected for analysis, and other information existing in scientific literature, and other sources such as official information. Moreover, since March and through September we documented the "Daily report on coronavirus covid-19 in Mexico" offered everyday by the Secretariat of Health to inform of the pandemic worldwide and domestically. The objective of this research is not to carry out statistical generalizations, but it does allow, from a qualitative point of view, analytical generalizations in contexts with analogous research problems and variables (Giménez, 2012).

6- The main research problem initially focused on stigma and discrimination against and among doctors (and against patients) and on the social construction of risk. The findings on stigma and discrimination will be published in another journal. The perception of risk and its relationship with the modification of medical practice was an axis of analysis that emerged during the field work. 


\section{Chart 1}

The data analysis process: ongoing analysis according to Grounded Theory (Glasser \& Strauss, 1967)

Literature review: previous health emergencies and Covid-19.
Provisional (previous) categories: stigma and discrimination toward and among doctors, stigma and discrimination against patients, perceived stigma in doctors, social representations of Covid-19, training on Covid-19 care, use of PPE, social construction of risk,
New questions and emergent categories: perception of risk, biomedical organizational culture, lack \&

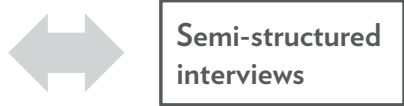

inadequacy of PPE perception, hospital reconversion management perception, work overload, changes in medical practice (consultation \& hospitalization), hospital spaces and self-isolation.

Data saturation.

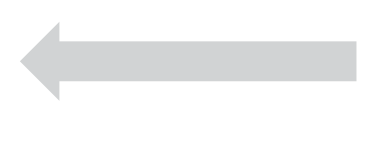

Reading interviews transcriptions many times

Atlas-ti codification \& analysis.

Axial coding (relating categories to each other)

Construction of themes/typologies

New literature review
Data triangulation with different informants and with the literature and the "Daily report on coronavirus Covid-19 in Mexico"
Revision of adequacy of translation
Translated to English by a professional

\section{Article writing}




\subsection{Research limitations and funding}

The limitations of the research lie in the conditions imposed by covid-19 in terms of "remote field work", bereft of participating observation and interviews with patients. Analogous limitations have been discussed by Vindrola-Padros et al. (2020) regarding the qualitative research on Covid-19 pandemic.

This article is the result of research funded by CONACYT (Mexican Science and Technology Council): "Support for scientific research, technological development and health innovation in light of the Covid-19 contingency".

\section{4. $\mathcal{E}_{\text {thical Considerations }}$}

All of the doctors interviewed were informed about the project, their right to confidentiality, to withdraw from the study and to receive the results via a document attached to a WhatsApp message, as well as verbally before the interview.

The guidelines established in the Helsinki Declaration were followed in the field-work and later use of the information. Informed consent, as well as authorization to record the phone call were requested from the informants. (Out of respect for their privacy, we did not use videocalls). We ensured the interviewees anonymity by refraining from recording personal data, and we only used code numbers in each extract of interviews appearing in this article.

We avoided in-depth inquiry into topics that could result in harm and informed the subjects who requested them, about strategies to care for mental health (of the medical staff) implemented by the Health Secretary and other institutions.

The institution where we work does not currently have an ethics committee and within anthropology research is uncommon in Mexico. Because this investigation was not conducted inside hospitals but via telephone maintaining confidentiality among a population not defined as vulnerable, this study can be classified as risk-free or minimally hazardous to interviewees.

The author has no conflicts of interest to declare.

\section{Findings: Risk Perception, Biomedical Organizational Culture and a New Medical Practice}

\subsection{The Arrival of a New Threat Makes Us All Vulnerable}

Hospital care in the context of the covid-19 pandemic has given rise to new fear and uncertainty in doctors regarding possible contagion. The data obtained shows that this situation is generalized in both hospitals dedicated to the care of covid-19 patients as well as those known as "hybrid hospitals". The sudden onset of SARS-Cov-2 has, indeed, entailed a shift from the perception of control and certainty gained from biomedical and epidemiological knowledge of the diseases doctors have studied 
and see regularly at the hospitals they work at. The main threat perceived as the outcome of a possible infection is the possibility of a fatal outcome, despite many of them not belonging to a high risk group, or the death of others whom they might infect, specifically relatives, which in itself is contingent on whether they live with them or not. This perception, in turn, is based on the information received through a media search, or in training sessions, as well as what circulates word of mouth and what they themselves observe at the hospitals they work at. Examples of the latter are those cases of patients who have died young and not presenting any comorbidity -some of which were HCW.

At the end of the day, nobody knows how they're going to die, which makes us all uneasy, the response in each patient. There are situations more closely linked to complications, but we have had 28-year-old patients with no comorbidities that have died, and you think, "That could have been me". (Resident-Internal Medicine/F)

While indeed some of the doctors interviewed are in the population group defined as at risk, and they state that they keep going to work because it is "my responsibility", this situation has implied the use of the "Covid-19 leave" and, in some cases, permanent discharge, of a significant number of doctors working at these hospitals, either because they belong to a specific age range that is vulnerable, or they present comorbidities, or because they choose not to be exposed to possible contagion. This situation, linked to the lack of overall personnel in the public health sector, has led to three types of institutional strategies to deal with the pandemic: hiring primarily new general practitioners, (Daily report on coronavirus covid-19 in Mexico, 14 May 2020), the mobilization of doctors who specialize in fields that are unrelated to infectious and contagious diseases like covid-19, and resorting to residents in training. In practice, the main burden of covid-19 care has fallen on the shoulders of resident physicians who are doing their specializations at these hospitals (Olmedo-Canchola et al., 2020), many of whom declare that it is a situation of inequality that subjects them to added pressure upon having to carry the lion's share of the work ${ }^{8}$ owing to reduced personnel, which in turn increases their potential exposure to covid-19.

For us it was mandatory; they send us a shift list, and you are practically forced to be there. We talked to the service administrator, but her answer was that her own hands were tied; there was nothing she could do about it. It's a problem residents will always face: we never know if we are students or workers in the eyes of the hospital. Right now we are the ones there by the bedside for covid-19 patients. (Resident-Psychiatry/M)

The perception of risk held by the doctors interviewed varies based on the department they work in and on their field of specialization and the status of the pandemic at the time they were interviewed, with perceived risk being the highest during the first few months of the health emergency. No differences have

7- In addition to the reference cited, and the empirical data obtained that reports this situation, the importance of the work of the residents was recognized in a graduation ceremony by the Secretary of Health of Mexico and other decision makers: https://www.dgcs.unam.mx/boletin/bdboletin/2021_174.html own departments, but their workload has dropped, although not the psychological pressure of their perceived risk of infection. 
been found due to age or gender. In general, specializations showing a lower risk of infection are internists, intensivists, and fields that have no actual contact with patients; the perception was higher in those who have to explore the respiratory tract, but also in doctors who are not used to working with infectious contagious diseases. This perception is tempered by the skills and technical knowledge they have, and the habit of using PPE to work with certain patients, and with familiarity with the covid-19 area and the possibility of being assigned to it.

We ear-eye-throat specialists are one of the fields of specialization most exposed to contagion because we work with the airways that transmit the virus. So we have been severely affected by having to perform physical explorations, and we avoid it as much as possible. We only explore when it is imperative to do so, because the risk is extremely high for health personnel. (Otolaryngologist/F)

My mind was at ease knowing I would be one of the last, not on the front line; but there were people, colleagues from other fields who were very worried. (Clinical Pathologist/F)

Many doctors said they had received some training after the first confirmed case in Mexico, and after the establishment of the National Drive for Healthy Distancing. Nevertheless, from their standpoint, this is not always enough or updated, and they deem it necessary to carry out their own searches to complement what they are given.

The first cases we took care of we practically used our own knowledge based on what we were reading up on, a sort of independent training. Proper training per se didn't start until the hospital reconversion. (Resident-Internal Medicine/F)

It is imperative to update the virtual course with information that arises as the pandemic progresses. These videos were recorded early on and are not updated. (Resident-Clinical Pathologist/M)

Most of the doctors interviewed had purchased their own PPE for work. They consider that frequently the non-covid-19 departments have not had access to the necessary material, for example facemasks. Both these doctors and those in the covid-19 care mentioned that the equipment provided by the institutions is not always of adequate quality or does not adapt to their needs. One example is the KN95 facemask instead of the N95, or goggles too. Some doctors anticipated shortages or not finding their size when the first cases in Mexico became known out of a fear of hoarding.

We ourselves have purchased around 90\% of the protective gear we have been using. Especially coveralls, face shields, filters which are fairly expensive, other equipment and even facemasks, since the ones provided weren't making me feel safe when entering a covid-19 area. (Resident-Internal Medicine/F) 
Though doctors feel that there is a greater possibility of becoming infected at work in the hospital and in areas designated for specialized covid-19 care, there are many who did say that infections in HCW occurs primarily in environments outside the hospital and less in exposure at the hospital. Those spending more time in the covid-19 area consider that there are fewer infections occurring in personnel working there that in those working in other departments. In both cases, they believe that exposure is greater because of fewer protective measures being observed by themselves or those surrounding them, either because they have less access to doing so or because of a more relaxed feeling of being "far away" from the virus.

I think that many of my colleagues were not infected in the covid-19 department, but outside of it. Inside we are all extremely cautious and you have to be really careful because you are aware that the virus is in there with you; I think people lower their guard on the outside because they don't feel its imminent presence. (Medical Internist/F)

It looks like some colleagues don't think anything is going on, but I wear my mask all the time, many of them remove it to talk amongst themselves in the office. Not me, when I am with them I wear my goggles and facemask. (General Practitioner/M)

An important process that is relevant is the point in time when the interviews were held. I noted that during the first months of the pandemic, doctors were much more afraid of becoming infected than now (September). In the beginning they developed protection strategies that entailed isolation, for example. The more adaptation to protocols and practice as time elapsed is yet another process that touches on the lower perception of risk.

The time when I felt depressed was when I wasn't with my children. I thought, "I'm not seeing that many patients anymore", and the ways in which I was taking care of myself had worked for two months. So, I went and got my kids and will continue abiding by the measures. I recovered my frame of mind. (General Practitioner/M)

This perception is conditioned by the aforementioned factors, for example, the field of specialization but also having contracted covid-19 or not. Those that did not contract covid-19 felt they had done things right and could continue. Those that had already contracted covid-19 have ambivalent feelings that are contingent on the course of the infection and the lesser or greater gravity of symptoms. Less risk for those lighter cases, less risk and possible short-term immunity; in the serious cases a greater degree of uncertainty. The doctors interviewed who worked the 2009 N1H1 influenza pandemic do not perceive less risk due to prior experience; they consider that they are now facing a much more virulent and unpredictable pandemic.

Some colleagues that have become infected with covid-19 feel more at ease because most of them experienced the slight version of the disease, and they think that they will not get sick again, which makes them feel better. However, we are now seeing reinfection cases ... 
according to the experience one acquires when dealing with a disease, when you wear your PPE to go in and examine your patients, and upon developing dexterity in your technical, professional and even emotional skills, you are better able to handle given situations. This produces peace of mind. (Resident-Internal Medicine/M)

\section{2. $T_{\text {he Medical Practice }}$}

A common perception held by many doctors is that covid-19 changes their bedside manner when caring for these patients; but it also affects outpatient care because, in fact, any patient arriving at the hospital must be treated as a potential bearer of covid- 19 .

At first, since the only thing being said was to keep a healthy distance, and because there was a filter in place to keep respiratory patients out, we thought we were dealing with patients who did not have covid-19... then, in the examining room, out of the blue, that patient coughs on you. You think, now what? I believe that the use of the facemask is fundamental. (Resident-Medical and Surgical Emergency Care/M)

Personal Protection Equipment is one of the main mediators in the clinical practice of the doctors

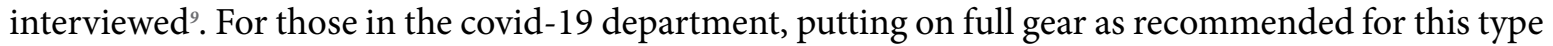
of medical care is perceived as physically taxing since it causes dehydration when they cannot drink water and there is increased perspiration, in addition to headaches, skin irritation due to constant friction, and even finding it impossible to use the bathroom during workdays that can last up to eight hours. These conditions foster discontent in doctors, which, together with the fear of becoming infected can lead to these doctors quitting their jobs.

Even just last week we had a meeting with the administration because a lot of people were reluctant to keep on wearing PPE; many of the residents backed down because of having to wear the PPE for hours on end. You cannot eat, go to the bathroom, or drink water because these are seriously ill patients and you might become infected. It is very uncomfortable and nobody is happy. (Resident-Internal Medicine/M)

In the doctors' office, PPE is perceived as an important factor in the medical care provided to the patient. The facemask, according to the testimonies, must be used during all doctors' visits; however, most doctors were not using them prior to the pandemic, save a few exceptions, such as with oncological patients. The pandemic has made it so facemasks are perceived as imperative in all interactions with patients and is frequently complemented by other elements, such as the face shield or goggles,

9- Prior to the pandemic no type of PPE material was used at all for outpatient care or hospitalization, except for specific cases of infectious or contagious diseases or when caring for immunosuppressed patients. In the field of intensive care, surgical facemasks, cap, boots and disposable scrubs. At present, in the departments of respiratory triage and in doctors' offices, triple layer facemasks and eye protection (goggles or face shield) as well as a waterproof long-sleeved scrubs and non-sterile disposable gloves are used. In patient hospitalization areas and intensive care units, the same equipment is used except for the surgical mask being substituted for an N95 respirator, and a disposable cap is optional (Gobierno de México, 2020). 
which were not habitually used. One of the difficulties reported is the limitation of giving a thorough physical exam wearing full PPE gear, which entails choosing between not doing so or doing so partially, wearing only scrubs, gloves and facemask but not the face shield or goggles. While the PPE is understood to be a way of avoiding the transmission of the infection by the patients, in some specific services it is used to avoid a possible infection from doctors to patients who are particularly vulnerable.

We do use PPE, especially when working with hemato-oncological children: scrubs, gloves, facemasks, cap; we don't always wear the goggles and face shield. PPE is standard gear, but not for such long periods. If you add in the face shield, for example, pressure on the forehead can be too much. (Resident-Pediatrics/F)

Yet another one of the difficulties documented is that the PPE changes important aspects, such as interaction between doctor and patient that, from the doctor's standpoint, is fundamental to the good flow of the visit. This is the case of gestures, volume of voice of doctor and patient (which is attenuated by PPE) that hinders communications and even causes difficulties in the use of specific devices as required by specializations.

The problem is that the ideal PPE is cumbersome for ordinary physical examinations, we do use it in covid-19 departments, but for scheduled visits we do not wear all of it, physical examination would not be possible. We use microscopes and the use of the face shield is impossible because we cannot see. We have to remove to be able to see through the microscope. (Otolaryngologist/F)

I have colleagues who do not touch the patient. When you don't touch the patient to examine him/her, they leave with the feeling of "the doctors didn't do anything for me." People are afraid to approach us, not always because they are afraid or unafraid, but you just can't. Patients come in with more fear than usual upon seeing you completely covered up, not being able to really see your face or facial expressions. I think that this also affects them greatly. (General practitioner/M)

In present conditions, care provided at doctor's offices is not frequent. Physicians don't face the customary treatment of patients that is normal for their practice, including sharing office space with several doctors, cramped space, nor assembly-line style service where they care for up to 24 patients per shift ${ }^{10}$. These conditions pose a challenge for doctors regarding the future of their practice, at least until such time as there is an efficacious vaccine that makes the pandemic less lethal at the worldwide level. On top of this, add in the lack of care for their regular patients because of suspension of office visits as a mitigation measure during the pandemic and owing to the reconversion of hospitals. In the present context of public medical services at the tertiary level, repercussions on health because of this lack of care will be dramatic and will entail increasing delays in consultations, treatments, tests and surgical interventions, as well as an increased number of critical patients and the deterioration of adequate conditions to offer care. 
I don't think we can go back to the way we used to see patients, at least not at my hospital. Our workspaces were double, meaning two doctors working in the same room, handling two patients at the same time because there was no other space. Right now that has become unimaginable. Spaces that we have to figure out how to adapt, how often we will we be seeing each patient, etc. (Resident-Psychiatry/M)

There have been no visits for pediatric endocrinology patients. The endocrinologists are with us in respiratory triage. We offer the service of pediatric internal medicine and we deal with patients with enzyme problems, giving them the enzyme that they need to lead a normal life and continue to live. It has been two months since we have not been able to do that. Some diseases have repercussions on the eyes, heart, kidneys (can affect kidney function), loss of some eyesight, and even a slight degree of heart failure. However, if the children were to become infected, I feel that they would either die or become candidates for hospitalization. (Resident-Pediatrics/M)

\section{Discussion}

The arrival of covid-19 has entailed a challenge for health care around the world and here in Latin America. In Mexico, the pandemic arrived three months after it was detected in China. The epidemiological traits that affect vulnerable groups, for example young people, have been different from what has been observed in other contexts, such as Europe (Gobierno de México, s/f; RENAVE, 2020). HCW have been one of the population groups most affected by the pandemic, either due to vulnerability to infection (the highest mortality rate for this group in the world is Mexico) (Chertorivski et al., 2020) or due to the repercussions that exposure has had on their mental health (Kang et al., 2020).

Over the last two decades, public spending in Mexico on health as a percentage of total public expenditure has fluctuated, showing a marked downward trend since 2004, which was accentuated as of 2013, with the ensuing repercussions on effective access to quality care in services, increasing out of pocket spending for the population (Secretaría de Salud, 2016, p. 16). By 2021 there will be an increase of $1.87 \%$ in the health sector budget. Despite this, Mexico maintains a budget gap of 3.2 points of PIB (at least 6\% of PIB is recommended). The reallocations of health spending, in general, are concentrated in increases in personal services and the payment of professional, scientific and technical services, and in cuts in subsidies, materials, equipment and infrastructure (Senyacen and Llanos, 2020). Yet another problem is that in Mexico City there is a concentration of most high specialization institutes in the country, and these are the ones that require High Technology Medical Equipment, hospitals that receive referrals from all over the country (Secretaría de Salud, 2016). An attempt is being made to create a universal public system (called INSABI), to increase universal health coverage beyond people's affiliations, but it has not yet been consolidated (Senyacen and Llanos, 2020). Under these structural conditions is where the doctors, interviewed at the hospitals that we studied, work. The pandemic affects preexisting social and job relations, not just rendering visible but also maximizing some of the gaps, such as dependence on residents to be able to function due to scarcity of personnel, increased now due to covid-19 leave, and this, linked to job subordination at the workplace, may have repercussions 
on their health (Gaona et al., 2018). Other studies underscore how having greater or lesser job experience, in similar scenarios such as SARS or covid-19, influences the risk of developing problems such as post-traumatic stress disorder due to exposure at the jobsite (Lancee et al., 2008; Lai et al., 2020), which from the anthropological perspective we can consider to be vulnerability caused by structural or social and political processes (Padoveze et al., 2019).

Under these structural conditions, the greater or lesser perception of risk of infection held by doctors is influenced by the following social and cultural processes: a) the closeness of age and comorbidities characteristics of at-risk groups $b$ ) the type of medical specialization and information and training received, c) the temporary nature of the pandemic and spaces of greater or lesser exposure, d) the PPE and protocols adapted, e) having or not had covid-19.

Both resident physicians and attending doctors perceive that covid-19 implies a new health risk given that they are acquiring it and have serious symptoms, as well as infecting family members who might become seriously ill, as was documented in Wuhan (Kang et al., 2020), in Colombia (Pedrozo-Pupo et al., 2020) and in Portugal (Peres et al., 2020) regarding the population at large. One interesting finding is that the doctors stated they feared a possible infection if they belonged or not to a group defined by epidemiology as at risk. This perception, from their standpoint, is linked to the present lack of evidence regarding treatment for covid-19, and linked to serious cases, or to those with fatal consequences that are not in keeping with said criteria and what they actually see in hospitals, such as young people. This specificity answers to the reality of how the pandemic is behaving in Mexico, affecting more young people than it does in other contexts, such as Europe (Gobierno de México, s/f; RENAVE 2020). Used to the paradigm of chronic disease in everyday health services, the arrival of this pandemic has brought with it new challenges in regard to the perception of risk held by doctors and the subjective negotiation on the possibility or not of being affected; as has occurred with other pandemics in the past, such as the 1918 flu and aids (Friedlander, 1990) or ebola (Gee \& Skovdal, 2017).

The perception of risk is associated to the process mentioned, to which we can add the field of specialization that a given doctor has trained in and his or her professional performance, and the habit of wearing PPE. In various cases, doctors who had not in the past worked in intensive care units stated having a perception of stress linked to risk. Some of these aspects have been discussed in Liu et al. (2020) for the case of doctors without prior experience in infectious diseases dealing with covid-19 patients in China, but no study has yet considered the variable of the field of medical specialization.

The perception of risk held by doctors' decreases as time elapses and they become familiarized with caring for covid-19 and its protocols, with the information, and the measures provided by the health system, including PPE, and they begin to feel more adapted. The unpreparedness of the medical system has been documented as a source of perceived risk in other contexts (Peres et al., 2020). An evidence that coincides with other studies, in other countries, quantitative in nature and regarding SARS (Styra et al., 2008), consists of the ambivalence of greater risk perception based on professional performance as doctors in caring for covid-19 patients; and, at the same time, perceiving that they or their colleagues are more exposed in areas of socialization within the hospital, in other medical departments, or outside the hospital. Worth noting is a study carried out in China that documented that only $40 \%$ of infections in HCW occurred in hospital care (Liu et al., 2020) and in Mexico higher fatality is recorded for personnel with a "Covid-19 Leave" (1.3\%) compared to active personnel (0.7\%) (Daily report on coronavirus covid-19 in Mexico, October 14, 2020). The perception of risk and/or immunity is a construct that in 
these cases functions relationally, based on the possibility - constructed subjectively (Douglas, 1986) - of being more or less exposed, based on the perception of high exposure by virtue of working at a hospital providing covid-19 care, and perceived less exposure outside the hospital. This also applies to the greater perception of risk in the area of covid-19 patients as compared to non-covid-19 patients. This perception per se is linked to epidemiological narrative on the pandemic and the manners of infection prevention, with the management of BOC regarding the use of PPE and prophylactic measures adopted by doctors. Other current studies have found that the doctors (Chew et al., 2020) who work in high risk areas have lower perceived levels of stress because they are aware that they are going to work with patients with a diagnosis or suspicion of covid-19, in areas that have the necessary equipment and feeling that they are prepared and competent. In this regard, as we saw in the empirical data, the adaptation and training provided for treating physicians is a crucial aspect in the management of risk perception and, as indicated by Bielicki et al. (2020), in good performance on the job.

An important fact regarding the perception of risk is that those respondents who have already had covid-19 at the time of responding do not know if reinfection is a possibility and assume that covid-19 produces relative immunity that hinders reinfection, at least in the mid-term. ${ }^{11}$ Some related studies on SARS indicate that professionals who have become ill with the infection were more worried about death, discrimination, and quarantine than those who had never been infected (Ho et al., 2005), and had consequences to their mental health (Wing \& Leung, 2012). This evidence regarding SARS is contrary to the immunity perceived by the doctors interviewed for this study who had slight cases of covid-19 but might guide us for intervening with those who had serious cases and may be suffering post-traumatic stress, as studies like Lai et al. (2020) describe.

One of the main findings of the investigation refers to how the perception of risk as linked to risk management and hospital BOC, as well as public policy, influence the clinical practice of the doctors who are the subjects of this study. HIV is one of the infections most studied regarding impact on potential and real changes in medical practice, with literature that emerged from the first decades since its onset (Taylor et al., 1990). There are few qualitative studies that have researched the perception of risk and its association to the will of doctors to work with infectious diseases in health emergencies (Gee \& Skovdal, 2017). The use of PPE in providing adequate medical care is reported for the covid-19 wing of a hospital floor as well as for intensive care units and outpatient areas. Some of the results coincide with the only qualitative study in existence to date that touches on some aspects of this problem, such as fatigue or discomfort in work performance due to PPE (Liu et al., 2020). Our research underscores how $\mathrm{PPE}$ as associated to risk perception influences doctor-patient communication in a cultural context that hinges greatly on a communication model that emphasizes the need for an exchange of gestures between doctors and patients, as well as difficulties to hear one another, in addition to hindrances in the use of certain diagnostic or exploratory devices. Another important finding resides in risk management after hospital reconversion and the prioritization of covid-19 patients and urgent care has excluded patients whose regular doctors are at the hospitals studied in Mexico City. The doctors interviewed point out the difficulties that they will face in their clinical practice once their regular patients come back, who prior to the pandemic were taken care of in mass consultation situations by scarce numbers of HCW. Covid-19 presents like a metaphor of the contradictions in the current public health system, rendered precarious 
because of policies to remove investment and a restructuring that has been ongoing for decades now, making clear the difficulties in providing adequate care. This, from the standpoint of the respondents, is more evident now since sharing clinical spaces among several doctors and seeing some 24 patients a day per doctor, as was habitual, may compromise clinical practice in a notoriously differentiated manner, as well as the health of patients. All this, even with the promise of a vaccine soon, and infection prevention protocols being laxer, and the fear of covid-19 and its consequences being more digestible than it is at present. Covid-19 may in time be less devastating in these future conditions, but it has arrived in the world of social relations and the perceptions of risk in the arena of health care are here to stay. Whether the perception of risk and its management deepens vulnerability for the health of doctors and patients or not will be contingent on the will to generate, through research, social and cultural knowledge about this and on acting to adapt it; which indisputably entails transforming the structural conditions in place prior to the pandemic aggravated upon its arrival.

\section{$F_{\text {inal Considerations }}$}

The arrival of covid-19 epidemic in Mexico has highlighted some of the old limitations of hospital medical care, in the Mexican public health system, producing at the same time the updating of contradictions in their biomedical organizational cultures. These contradictions appeal to priorities defined by the dominant epidemiology and focused on solving certain challenges in medical practice within the covid-19 context, but also to possibilities of action for equitable medical care and in decent and save working conditions for health personnel.

The dominant epidemiological approach is based on the study of risk factors and behaviors of people, which includes doctors, regarding a specific health/disease/care-prevention process. Although these approaches are important and allow making proposals to modify, for example in this case, greater or lesser exposure to Covid through proper use of EPP, they often are distanced from the analysis of the articulations between cultural and structural process. The proposals, with an applied nature, derived from our research should not be focused only on the modification of the individual's behavior, from an overdetermined cultural or psychological perspective, but also on the interlinks between culture/structure/subject that make possible underline what conditions their behavior. In some cases, such as this one with covid-19, there are emerging and unknown social processes that foster new fears and uncertainties, but these are always anchored to social and power relations and pre-existing cultural backgrounds. To elucidate this, it is essential to consider the point of view and praxis of the social actors, in this case the doctors who treat covid-19. Local epidemiology's, public health policies and biomedical organizational cultures are inscribed in them.

In light of the results discussed, we will propose some recommendations that we consider may contribute to the intervention regarding risk, its perception and management by biomedical organizational cultures at tertiary-level hospitals in Mexico City.

There is a pressing need to hire medical specialists for an indefinite period at tertiary-care hospitals, as there is also to build new hospitals that will enable handling a greater number of patients in appropriate conditions to resolve their health needs, not only in the context of the current pandemic, but also in thinking about the inequalities that existed in pre-pandemic care and in similar future scenarios. 
We need ongoing training for doctors regarding covid-19 and guaranteeing updates as new scientific findings emerge. Equally important is to insist on the use of facemasks and physical distancing for contact among doctors during meetings, meals and in office spaces, but also, under the current conditions of the pandemic, insist on measures to be taken in their social lives outside the hospital. PPE must adapt to the existing communication models in the Mexican context and be based on the creation of new designs that facilitate both the use of diagnostic and examination devices, that will improve verbal communication and interaction through gestures. Adaptation in the use of PPE to new evidence is fundamental if we are to minimize the impact on physical strain and on job satisfaction.

\section{References}

Berger, P., Luckmann, T. (1966) The Social Construction of Reality. A Treatise in the Sociology of knowledge. Penguin Books.

Bielicki, J. A., Duval, X., Gobat, N., Goossens, H., Koopmans, M., Tacconelli, E., \& van der Werf, S. (2020). Monitoring approaches for health-care workers during the COVID-19 pandemic. The Lancet Infectious Diseases, 20 (10): e261-e267. https://doi.org/10.1016/S1473-3099(20)30458-8

Chertorivski, S., Córdova, J. A., Frenk, J., Juan, M., Narro, J. \& Soberón, G. (2020). La gestión de la epidemia en México: Covid-19 análisis preliminar y recomendaciones urgentes. Consejo Consultivo Ciudadano.

Chew, Q. H., Chia, F. L. A., Ng, W. K., Lee, W. C. I., Tan, P. L. L., Wong, C. S., Puah, S.H., Shelat, V.G., Seah, E.J.D., Huey, C.W.T., Phua, E.J. \& Sim, K. (2020). Psychological and coping responses to COVID-19 amongst residents in training across ACGME-I accredited specialties in Singapore. Psychiatry Research, 290. https://doi.org/10.1016/j.psychres.2020.113146

Douglas, M. (1986). Risk Acceptability According to the Social Sciences. Russell Sage Foundation.

Fantin, R. Brenes-Camacho G. y Barboza-Solis, C. (2021). Defunciones por Covid-19: distribución por edad y universalidad de la cobertura médica en 22 países. Rev Panam Salud Publica, 45 (42) https://doi.org/10.26633/RPSP.2021.42

Friedlander, W. J. (1990). On the Obligation of Physicians to Treat AIDS: Is There a Historical Basis? Reviews of Infectious Diseases, 12 (2):191-203.

Gaona, L., Estrada, R., Tomp, P. \& Rizo, J. (2018). La importancia de la salud en los médicos residentes y su relación con la calidad y seguridad del paciente. Boletín CONAMED-OPS, 3 (18). http:// www.conamed.gob.mx/gobmx/boletin/pdf/boletin18/importancia_salud.pdf

Gee, S. \& Skovdal, M. (2017). The role of risk perception in willingness to respond to the 2014-2016 West African Ebola outbreak: a qualitative study of international health care workers. Glob Health Research \& Policy, 2 (21). https://doi.org/10.1186/s41256-017-0042-y

Giménez, G. (2012). El problema de la generalización en los estudios de caso. Cultura y Representaciones Sociales, 7 (13).

Glasser, B. G. \& Strauss, A.L. (1967). The discovery of grounded theory: strategies for qualitative research. Aldine Transaction. 
Gobierno de México. (s.f.). Covid-19 México. Información General Nacional (Defunciones). Consultado el 10 de septiembre de 2020. https://coronavirus.gob.mx/exceso-de-mortalidad-en-mexico/\#

Gobierno de México. (2020). Lineamiento técnico de uso y manejo del equipo de protección personal ante la pandemia de Covid-19, 12 May 2020. Gobierno de México. https://coronavirus.gob.mx/ wp-content/uploads/2020/05/Lineamiento_uso_manejo_EPP_COVID-19.pdf

Ho, S. M. Y., Kwong-Lo, R. S. Y., Mak, C. W. Y. \& Wong, J. S. (2005). Fear of Severe Acute Respiratory Syndrome (SARS) Among Health Care Workers. Journal of Consulting and Clinical Psychology, 73 (2): 344-349. http://dx.doi.org/10.1037/0022-006X.73.2.344

Jackson-Fiho, J. M., Ávila-Assunção, A., Algranti, E., Garcia-Garcia, E., Saito, C. A. \& Maeno, M. (2020). A saúde do trabalhador e o enfrentamento da COVID-19. Revista Brasileira de Saúde Ocupacional, 45. http://dx.doi.org/10.1590/2317-6369ed0000120

Jaffré, Y. (2012). Towards an anthropology of public health priorities: maternal mortality in four obstetric emergency services in West Africa. Social Anthropology, 20 (1): 3-18. https://doi. org/10.1111/j.1469-8676.2011.00190.x

Kang, L., Ma, S., Chen, M., Yang, J., Wang, Y., Li, R., Yao, L., Bai, H., Cai, Z., Yang, B.X., Hu, S., Zhang, K., Wang, G., Ma, Ci \& Liu, Z. (2020). Impact on mental health and perceptions of psychological care among medical and nursing staff in Wuhan during the 2019 novel coronavirus disease outbreak: A cross-sectional study. Brain, Behavior, and Inmunity, 87:11-17. https://dx.doi. org/10.1016\%2Fj.bbi.2020.03.028

Kim, C. S., Lynch, J. B., Cohen, S., Neme, S., Staiger, T. O., Evans, L., Pergam, S.A., Liu, C., BrysonCahn, C. \& Dellit, T. H. (2020). One Academic Health System's Early (and Ongoing) Experience Responding to COVID-19: Recommendations from the Initial Epicenter of the Pandemic in the United States. Academic Medicine, 95 (8): 1146- 1148. https://doi.org/10.1097/ acm.0000000000003410

Lai, J., Ma, S., Wang, Y., Cai, Z., Hu, J., Wei, N., Wu, J., Du, H., Chen, T., Li, R., Tan, H., Kang, L., Yao, L., Huang, M., Wang, H., Wang, G., Liu, Z. \& Hu, S. (2020). Factors Associated with Mental Health Outcomes Among Health Care Workers Exposed to Coronavirus Disease 2019. JAMA Network Open, 3 (3): e203976. https://doi.org/10.1001/jamanetworkopen.2020.3976

Lancee, W. J., Maunder, R. G. \& Goldbloom, D. S. (2008). Prevalence of psychiatric disorders among Toronto hospital workers one to two years after the SARS outbreak. Psychiatric Services, 59 (1): 91-95. https://ps.psychiatryonline.org/doi/abs/10.1176/ps.2008.59.1.91

Liu, Q., Luo, D., Haase, J. E., Guo, Q., Wang, X. Q., Liu, S., Xia, L., Liu, Z., Yang, J. \& Yang, B. X. (2020). The experiences of health-care providers during the COVID-19 crisis in China: a qualitative study. Lancet Global Health, 8: 790-798. https://doi.org/10.1016/S2214-109X(20)30204-7

Lupton, D. (1999). Risk. Routledge.

Menéndez, E. (2014). Las instituciones y sus críticos o la costumbre de polarizar la realidad: el caso de la influenza A (H1N1). Salud Colectiva, 10 (1): 15-39. https://doi.org/10.18294/sc.2014.206

Muñoz, R. (2018). Estigma estructural, adherencia al tratamiento antirretroviral y cultura organizacional de cuidados en la atención hospitalaria en VIH y sida en Guayaquil, Ecuador. Andamios, 15 (36): 311-341. https://doi.org/10.29092/uacm.v15i36.612

Nichter, M. (2006). Reducción del riesgo: una preocupación central para la antropología médica. Desacatos, (20): 109-132. https://doi.org/10.29340/20.1033 
Olmedo-Canchola VH, Bazán-Miranda, G, Torres-Carrillo J, Ramírez-Tejeda M y col. (2020) Los médicos residentes de la UNAM, piezas clave frente a la pandemia por COVID-19. Med Int Méx, 36 (6): 841-851 https://doi.org/10.24245/mim.v36i6.4594

Padoveze, M. C., Juskevicius, L. F., Santos, T. R., Nichiata, L. I., Ciosak, S. I. \& Bertolozzi,

M.R. (2019). The concept of vulnerability applied to Healthcare-associated Infections. Revista Brasileira de Enfermagem, 72 (1): 299-303. http://dx.doi.org/10.1590/0034-7167-2017-0584

Pedrozo-Pupo, J. C., Pedrozo-Cortés, M. J. \& Campo-Arias, A. (2020). Perceived stress associated with COVID-19 epidemic in Colombia: an online survey. Cadernos de Saúde Pública. 36 (5): e00090520. https://doi.org/10.1590/0102-311x00090520.

Peres, D., Monteiro, J., Almeida, M. \& Ladeira, R. (2020). Risk perception of COVID-19 among Portuguese healthcare professionals and the general population. Journal of Hospital Infection, 105 (3): 434-437. https://doi.org/10.1016/j.jhin.2020.05.038

RENAVE. (2020). Informe $n^{\circ}$ 40, Situación de COVID-19 en España: Casos diagnosticados a partir 10 de mayo, Informe COVID-19, 13 August 2020. Instituto de Salud Carlos III. https://www. isciii.es/QueHacemos/Servicios/VigilanciaSaludPublicaRENAVE/ EnfermedadesTransmisibles/Documents/INFORMES/Informes\%20COVID-19/Informe\%20COVID-19.\%20N\%C2\%BA\%2039_13agosto2020_ISCIII.pdf

Schreier, M (2012). Qualitative Content. Analysis in Practice. Sage

Secretaría de Salud. (2016). Informe sobre la salud de los mexicanos 2016, Diagnóstico General del Sistema Nacional de Salud. Secretaría de Salud.

Senyacen, J. and Llanos, A. (2020). Presupuesto para salud 2021: Prioridad en la creación de plazas médicas. Centro de Investigación Económica y Presupuestaria (CIEP).

Singer, M. (2009). Pathogens Gone Wild? Medical Anthropology and the "Swine Flu" Pandemic. Medical Anthropology: Cross-Cultural Studies in Health and Illness, 28 (3): 199-206. https:// doi.org/10.1080/01459740903070451

Styra, R., Hawryluck, L., Robinson, S., Kasapinovic, S., Fones, C. \& Gold, W. (2008). Impact on health care workers employed in high-risk areas during the Toronto SARS outbreak. Journal of Psychosomatic Research, 64 (2): 177-183. https://doi.org/10.1016/j.jpsychores.2007.07.015

Sudabby, R., (2006). From the editors: What grounded theory is not. The Academy of Management Journal, 49(4): 633-642.

Taylor, K. M., Eakin, J. M., Skinner, H. A., Kelner, M. \& Shapiro, M. (1990). Physicians' perception of personal risk of HIV infection and AIDS through occupational exposure. Canadian Medical Association Journal, 143 (6): 493-500.

Venables, E. and Umberto P. (2017). Introduction, Engaging Anthropology in an Ebola Outbreak, Cases studies from West Africa. Anthropology in Action, 24 (2): 1-8. https://doi.org/10.3167/ aia.2017.240201

Vindrola-Padros, C., Chisnall, G., Cooper, S., Dowrick, A., Djellouli, N., Symmons, S.M., Martin, S., Singleton, G., Vanderslott, S., Vera, N. \& Johnson, G. A. (2020). Carrying Out Rapid Qualitative Research During a Pandemic: Emerging Lessons From COVID-19. Qualitative Health Research, 30 (14): 2192 -2204. https://doi.org/10.1177\%2F1049732320951526

Wing, Y. K. \& Leung, C. M. (2012). Mental health impact of severe acute respiratory syndrome: a prospective study. Hong Kong Medical Journal, 18 (3): 24-27 